\title{
THE RATE OF TUBERCULOSIS INFECTION IN HIV POSITIVE PATIENTS IN RELATION TO CD4 COUNT
}

\author{
B.Sreekanth'ㄹ, T.K .Chakraverti², K.Saileela ${ }^{3}$, K.Sateesh ${ }^{4}$, Ravi Shankar Reddy ${ }^{5}$, P.Lakshmivasantha ${ }^{6}$.
}

1. Assistant Professor, Department of Microbiology, Kamineni Institute of Medical Sciences.
2. Assistant Professor, Department of Microbiology, Kamineni Institute of Medical Sciences.
3. Professor \& H.O.D, Department of Microbiology, Kamineni Institute of Medical Sciences.
4. Assistant Professor, Department of Microbiology, Kamineni Institute of Medical Sciences.
5. Associate Professor, Department of Microbiology, Kamineni Institute of Medical Sciences.
6. Associate Professor, Department of Microbiology, Kamineni Institute of Medical Sciences.

\section{CORRESPONDING AUTHOR:}

B. Sreekanth, KIMS, Narketpally, Nalgonda District, Andhra Pradesh

E-mail: sree076@gmail.com

\begin{abstract}
INTRODUCTION: Tuberculosis is the most common HIV-related opportunistic infection in India, and caring for patients with both diseases is a major public health challenge, which places an immense burden on health care systems and poses particular diagnostic and therapeutic challenges, increasing the risk of treatment failure, relapse and death. Estimates by the World Health Organization (WHO) indicate that there are more than 9 million new active cases of TB and close to 2 million deaths per year. MATERIALS AND METHOD: The present retrospective study was conducted for a period of one year. HIV status was confirmed for patients attending voluntary counselling and testing centre (VCTC). HIV positive patients were referred to designated microscopic centre (DMC) for sputum examination for AFB and ART centre for estimation of CD4 count and necessary relevant investigations were carried out for extrapulmonary tuberculosis (EPTB). RESULTS: Out of 682 HIV positive patients, 93(13.6\%) cases were diagnosed with pulmonary tuberculosis. Extrapulmonary tuberculosis was detected in 16 (2.3\%) patients. The commonest form of EPTB was cervical adenitis detected in13 (1.9\%) of cases and pleural effusion in $3(0.4 \%)$ of cases respectively. The mean CD4 count was 208 cells/ $\mu$ in patients with pulmonary tuberculosis (PTB) and 192cells / $\mu \mathrm{l}, 162$ cells $/ \mu \mathrm{l}$ in patients with cervical adenitis and pleural effusion. CONCLUSIONS: Further reduction of CD4 count occurs in dually infected patients. Early diagnosis and prompt institution of ART and ATT reduces mortality and morbidity significantly.
\end{abstract}

INTRODUCTION: Tuberculosis (TB) and human immunodeficiency virus (HIV) constitute the main burden of infectious disease in resource-limited Countries ${ }^{1}$. Persons infected with HIV are particularly susceptible to tuberculosis, both from the reactivation of latent infection and from new infection with rapid progression to active disease ${ }^{2}$. An individual who is HIV-positive has 10 times increased risk of developing TB compared to an HIV-negative person the life time risk is $50 \%$ for an HIV-positive person and 5-10\% for an HIV-negative person ${ }^{3}$. Estimates by the World Health Organization (WHO) indicate that there are more than 9 million new active cases of TB and close to 2 million deaths per year and that 2.6 million new cases of HIV infection and 1.8 million AIDSrelated deaths occur per year ${ }^{1}$. In India alone about 2.5 million people are currently infected with 
HIV of whom $40 \%$ are also coinfected with TB4. TB infection contributes to further reduction in CD4 cell count accelerating the progression of HIV infection to Acquired Immunodeficiency syndrome (AIDS) increasing the mortality and morbidity 5 . Despite the existence of effective drugs, TB continues to be a major health problem and kills more than a million a year6. Patients with HIV infection have a similar bacteriologic response to tuberculosis treatment as those who are not infected but have higher risks of recurrence and death. The influence of tuberculosis coinfection on the progression of HIV disease is controversial ${ }^{2}$. The present study was carried out to estimate the rate of TB in HIV patients and its relation to CD4 count.

MATERIALS AND METHODS: The present retrospective study was carried out over a period of one year from (1st January 2010 to December 2010) in the community care centre (CCC), Charlapalli, affiliated to Kamineni Institute of Medical Sciences, Sreepuram, Narketpally, Nalgonda Dist. Andhra Pradesh. Screening and confirmation of HIV status were carried out in patients visiting Integrated counseling and testing centers centre (ICTC) after pre-test counseling and written informed consent. HIV antibodies were tested by three ELISA/Rapid/Simple tests as per guide lines laid by NACO (Testing strategy III). Post test counseling was done for patients found to be positive for HIV. CD4 estimation was done by flow cytometry. Diagnosis of pulmonary tuberculosis was made by positive sputum AFB smear examination by Ziehl Nellsen technique as per RNTCP guidelines. Diagnosis of extra-pulmonary tuberculosis was made by relevant investigations like tissue biopsy, FNAC, and pleural fluid analysis.

RESULTS: Of the 682 HIV positive cases, 380 (55.7 \%) were males and 302 (45.1\%) were females. There were more patients in the $21-40$ years (70.6\%) of age group and least in the $>60$ years (1.3\%) age group (Table.1). Pulmonary tuberculosis was diagnosed in 93(13.6\%) patients and extrapulmonary tuberculosis (EPTB) was diagnosed in16 (2.3\%) patients of HIV positive group. The commonest extrapulmonary lesion was cervical lymphadenopathy reported in $13(1.9 \%)$ patients followed by pleural effusion in $3(0.4 \%)$ patients respectively.

CD4 count $<200 / \mu \mathrm{l}$ was found in $48(7.03 \%)$ of patients with pulmonary tuberculosis and 9 $(1.3 \%)$ of with EPTB. The mean CD4 count was 208 cells/ $\mu$ in patients with PTB while the mean CD4 count of 192cells / $\mu \mathrm{l}$ and 162 cells $/ \mu \mathrm{l}$ was found in patients with cervical adenitis and pleural effusion.

DISCUSSION: Tuberculosis is the most common opportunistic infection in HIV positive persons in India7. Maximum patients were in the age group of 21-40 years (70.6\%) and majorities were males. This is consistent with the findings of other studies ${ }^{4}$. Unprotected heterosexual transmission was the commonest mode of transmission as was reported in other studies ${ }^{8}$. The commonest type of TB found among HIV patients was pulmonary TB accounting for $13.6 \%$ of cases. Studies conducted by Christopher C. Affusim ${ }^{9}$ et al and Peters et al ${ }^{10}$ demonstrated pulmonary tuberculosis was the commonest type of TB in HIV positive patients. The World Health Organization (WHO) reported that among the 9.27 million incident cases of tuberculosis in 2007, an estimated 1.37 million $(14.8 \%)$ occurred in HIV-positive patients ${ }^{11}$.In a study conducted between January and September 2006, in the six Indian states with the highest HIV prevalence (Andhra Pradesh, Karnataka, Maharashtra, Manipur, Nagaland, and Tamil Nadu); tuberculosis was diagnosed in $22.3 \%$ and 
$23.9 \%$ of patients in these groups, respectively ${ }^{12}$. EPTB was diagnosed in $2.3 \%$ of the HIV positive patients, the commonest being cervical adenitis $(1.9 \%)$ of the cases followed by pleural effusion $(0.4 \%)$ of the cases. This was consistent with other studies ${ }^{9,13}$. The mean CD4 count of HIV patients with EPTB was $<200$ cells $/ \mu$ l when compared to HIV patients with pulmonary tuberculosis. Our study also demonstrates that significant decline in CD4 lymphocyte count results in progressive immunosuppression resulting in growth and local spread of M.tuberculosis. Hence extra pulmonary disease is more common.

\section{REFERENCES:}

1. Pawlowski A, Jansson M, Skold M, Rottenberg ME, Kallenius G. Tuberculosis and HIV CoInfection. PLoS Pathogens 2012; 8:1-7.

2. Markowitz N, Hansen NI, Hopewell PC, Glassroth J, Kvale PA, Mangura BT et al. Incidence of Tuberculosis in the United States among HIV-infected Persons. Ann Intern Med 1997; 126:123-32.

3. Affusim CC, Kesieme BE, Abah VO. The Pattern of Presentation and Prevalence of Tuberculosis in HIV-Seropositive Patients Seen at Benin City. Nigeria. ISRN Pulmonology 2012.

4. Ghiya R, Naik E, Casanas B, Izurieta R, Marfatia Y.C linici epidemiological profile of HIV/TB coinfected patients in Vadodara, Gujarat. Indian J Sex Transm Dis 2009; 30:10-5.

5. Wanchu A, Kuttiatt VS, Sharma A, Singh S, Varma S. CD4 cell count recovery in HIV/TB infected patients versus uninfected HIV patients. Indian J Pathol Microbiol 2010; 53(4):7459.

6. Bhagyabati Devi S, Santa Naorem, Jeetenkumar Singh T, Birendra Singh Ksh, Lallan Prasad, Shanti Devi Th. HIV and TB Co-infection JIACM 2005;6(3):220-3.

7. Swaminathan S, Sangeetha M, Arunkumar N, Menon P.A, Thomas B, Shibi K et al. Pulmonary tuberculosis in HIV positive individuals: Preliminary report on clinical features and response to treatment. Ind.J Tub 2002; 49:189-94.

8. Ajay Jaryal, Rajeev Raina, Malay Sarkar, Ashok Sharma. Manifestations of tuberculosis in HIV/AIDS patients and its relationship with CD4 count. Lung India 2011; 28(4):263-6

9. Christopher C. Affusim, Emeka Kesieme, Vivien O. Abah. The pattern of presentation and prevalence of tuberculosis in HIV seropositive patients seen at benin city, Nigeria. ISRN Pulmonology 2012.

10. Peters EJ, Ekott JU, Eshiet GA, Ayanechi CC. Tuberculosis in Calabar: a ten-year review (1994-2003). Niger J Med 2005; 14(4):381-5.

11. Swaminathan S, Padmapriyadarsini C, Narendran G. HIV-associated tuberculosis: clinical update. Clin infect Dis 2010; 50(10):1377-86.

12. Steinbrook R. Tuberculosis and HIV in India. N Engl J Med 2007; 356:1198-99.

13. Ahmad Z, Shameem M. Manifestations of Tuberculosis in HIV Infected Patients. JIACM 2005; 6(4): 302-5. 


\section{ORIGINAL ARTICLE}

Table. 1: Age wise distribution of HIV infected cases

\begin{tabular}{lcccc}
\hline Age (years) & HIV Positive patients & $\%$ & Coinfected patients & $\%$ \\
\hline $1-20$ & 39 & 5.7 & 11 & 10 \\
$21-40$ & 482 & 70.6 & 63 & 57.7 \\
$41-60$ & 152 & 22.2 & 32 & 29.3 \\
$>60$ & 9 & 1.3 & 3 & 2.7
\end{tabular}

Table. 2: Distribution of pulmonary and extra pulmonary tuberculosis

CD4/ $\mu$ l Pulmonary TB sputum (+) cervical lymphadenopathy Pleural effusion

$\begin{array}{llll}<200 & 48 & 06 & 03\end{array}$

$\begin{array}{llll}>200 & 45 & 07\end{array}$

$\begin{array}{llll}\text { Mean } \mathrm{CD} 4 / \mu \mathrm{l} & 208 & 192 & 162\end{array}$ 